\title{
Racemic carbohydrates - fact or fiction?
}

\author{
Alexander Senning \\ Department of Chemistry, Building 207, Technical University of Denmark, DK-2800 Kgs. \\ Lyngby, Denmark \\ E-mail: aes@kemi.dtu.dk
}

\begin{abstract}
Chemical Abstracts Service has developed unsound practices in the naming and handling of simple carbohydrates such as aldopentoses $\mathbf{1}$, aldohexoses 2, and ketohexoses 3. Typically, the common name glucose is sometimes, inappropriately, interpreted as meaning DL-glucose DL-2d. Thus, a considerable number of CA names and registry numbers have been created for nonexisting racemic carbohydrates and linked to irrelevant references which, moreover, in many cases cannot be retrieved by the SciFinder Scholar program.
\end{abstract}

Keywords: Aldohexoses, aldopentoses, carbohydrates, chemical abstracts, 2-ketohexoses, racemates, registry numbers

\section{Introduction}

Off hand it is easy to dismiss racemic carbohydrates such as DL-glucose DL-2d or DL-ribose DL1c as most unlikely objects of chemical endeavor - the non-enantiospecific or partially nonenantiospecific stepwise construction of, say, pentoses or hexoses will never lead to racemates, but rather to complicated diastereomeric mixtures. Should a preexisting single carbohydrate stereoisomer be subjected to non-stereospecific chain elongation a mixture of anomers, but never a racemate, would be produced. As far as theoretical chemistry is concerned it is hard to imagine an uncharted property of a racemic carbohydrate worth the computational effort. Finally, biological studies of racemic carbohydrates would add nothing to the already extensive knowledge of the natural enantiomers and their unnatural counterparts. For accounts of organic stereochemistry in general, cf. Ref., ${ }^{1}$ for the systematics and stereochemistry of the common monosaccharides, cf. Ref. ${ }^{2}$ Thus, a database search for racemic carbohydrates should give zero results or nearly so, or should it? 


\section{Results and Discussion}

All searches mentioned in the following were performed on September 26, 2007 or later with SciFinder Scholar 2007. ${ }^{3}$ Tables 1, 2, and 3 show how some of the common monosaccharides are treated in the Chemical Abstracts System. ${ }^{4}$

Table 1. Aldopentoses 1 in Chemical Abstracts

\begin{tabular}{|c|c|c|c|}
\hline CA name [other names] & $\mathrm{RN}$ & $\begin{array}{c}\text { number of references } \\
\text { indicated in the } \\
\text { Registry File }\end{array}$ & $\begin{array}{l}\text { number of references } \\
\text { retrieved in the CA } \\
\text { File }\end{array}$ \\
\hline $\begin{array}{l}\text { D-arabinose D-1a [D-(-)-arabinose, (-)- } \\
\text { arabinose] }\end{array}$ & $10323-20-3$ & $\sim 2162$ & 2162 \\
\hline L-arabinose L-1a [L-(+)-arabinose] & $5328-37-0$ & $\sim 2680$ & 2680 \\
\hline $\begin{array}{l}\text { arabinose DL-1a [DL-arabinose, }( \pm)- \\
\text { arabinose, dl-arabinose] }\end{array}$ & $147-81-9$ & $\sim 7824$ & 10031 \\
\hline D-lyxose D-1b & $1114-34-7$ & $\sim 664$ & 664 \\
\hline L-lyxose L-1b & $1949-78-6$ & $\sim 160$ & 160 \\
\hline lyxose DL-1b $[( \pm)$-lyxose, dl-lyxose $]$ & $65-42-9$ & $\sim 452$ & 472 \\
\hline D-ribose D-1c [ribose] & $50-69-1$ & $\sim 6597$ & 9249 \\
\hline L-ribose L-1c & $24259-59-4$ & $\sim 201$ & 201 \\
\hline $\begin{array}{l}\text { ribose DL-1c [DL-ribose, }( \pm) \text {-ribose, dl- } \\
\text { ribose] }\end{array}$ & $34466-20-1$ & $\sim 27$ & 28 \\
\hline $\begin{array}{l}\text { D-xylose D-1d }[\mathrm{D}-(+) \text {-xylose, } \quad(+)- \\
\text { xylose, wood sugar }]\end{array}$ & $58-86-6$ & $\sim 16623$ & 16626 \\
\hline L-xylose L-1d & $609-06-3$ & $\sim 423$ & 423 \\
\hline $\begin{array}{l}\text { xylose DL-1d [DL-xylose, }( \pm) \text {-xylose, } \\
\text { dl-xylose] }\end{array}$ & $25990-60-7$ & $\sim 95$ & 98 \\
\hline
\end{tabular}

CA's treatment is problematic in a number of cases and for several reasons. Let us first take the CA name arabinose 1a with RN [147-81-9] which is defined as being synonymous with the non-CA names DL-arabinose, $( \pm$ )-arabinose, and dl-arabinose (cf. Table 1). As used by mainstream chemists or other professionals in any imaginable rational context 'arabinose' will mean 'D-arabinose', 'L-arabinose' or 'arabinose regardless of its D- or L-configuration', but never the racemate DL-arabinose DL-1a. In the extremely rare case where anybody would wish to discuss DL-arabinose DL-1a it would, for obvious reasons, be called 'DL-arabinose' and never 'arabinose'. An additional, unexpected problem crops up when one notes that the number of references retrieved in the CA File ${ }^{4}$ for DL-2c, DL-2d, DL-2h, DL-3a, and DL-3c dramatically outnumbers the number of references shown in the Registry File ${ }^{4}$ for the registry number in question. Thus, the CA name 'fructose' is identified as DL-3a, RN [30237-26-4], in the Registry File $^{4}$ with $\sim 76$ associated references. This same registry number, however, retrieves an unwieldy 
and for all practical purposes irrelevant 10623 references in the CA File, a remarkable flaw in the search capabilities of SciFinder Scholar which renders the user unable to inspect the implied 76 'genuine' references. At the same time one should note that the non-CA name 'fructose' is by CA, and rightly so, regarded as synonymous with the CA name 'D-fructose' [57-48-7] (cf. Table $3)$.

Table 2. Aldohexoses 2 in Chemical Abstracts

\begin{tabular}{|c|c|c|c|}
\hline CA name [other names] & $\mathrm{RN}$ & $\begin{array}{l}\text { number of } \\
\text { references } \\
\text { indicated in the } \\
\text { Registry File }\end{array}$ & $\begin{array}{l}\text { number of } \\
\text { references } \\
\text { retrieved in the } \\
\text { CA File }\end{array}$ \\
\hline D-allose D-2a & $2595-97-3$ & $\sim 371$ & 371 \\
\hline L-allose L-2a & $7635-11-2$ & $\sim 31$ & 31 \\
\hline allose DL-2a [dl-allose] & $6038-51-3$ & $\sim 263$ & 307 \\
\hline D-altrose D-2b & $1990-29-0$ & $\sim 187$ & 187 \\
\hline L-altrose L-2b & $1949-88-8$ & $\sim 36$ & 36 \\
\hline altrose DL-2b [dl-altrose] & $5987-68-8$ & $\sim 247$ & 247 \\
\hline $\begin{array}{lcc}\text { D-galactose } \quad \text { D-2c } & {[\mathrm{D}-(+) \text {-galactose, }} & (+)- \\
\text { galactose, galactose }] & \end{array}$ & $59-23-4$ & $\sim 25280$ & 25292 \\
\hline L-galactose L-2c & $15572-79-9$ & $\sim 395$ & 395 \\
\hline $\begin{array}{l}\text { galactose DL-2c [DL-galactose, }( \pm) \text {-galactose, } \\
\text { dl-galactose] }\end{array}$ & $26566-61-0$ & $\sim 81$ & 12876 \\
\hline $\begin{array}{l}\text { D-glucose D-2d [D-(+)-glucose, (+)-glucose, } \\
\text { glucose, dextrose, meritose, corn sugar, grape } \\
\text { sugar }]\end{array}$ & $50-99-7$ & $\sim 209901$ & 314248 \\
\hline L-glucose L-2d [L-(-)-glucose, l-glucose] & $921-60-8$ & $\sim 889$ & 889 \\
\hline glucose DL-2d [DL-glucose, $( \pm)$-glucose] & $58367-01-4$ & $\sim 33$ & 736 \\
\hline D-gulose D-2e & $4205-23-6$ & $\sim 150$ & 150 \\
\hline L-gulose L-2e & $6027-89-0$ & $\sim 81$ & 81 \\
\hline gulose DL-2f [DL-gulose] & $19163-87-2$ & $\sim 236$ & 248 \\
\hline D-idose D-2g & $5978-95-0$ & $\sim 100$ & 100 \\
\hline L-idose L-2g & $5934-56-5$ & $\sim 53$ & 53 \\
\hline DL-idose DL-2g & $2152-76-3$ & $\sim 187$ & 195 \\
\hline $\begin{array}{l}\text { D-mannose } \quad \text { D-2h } \quad[D-(+)-\text { mannose, } \quad(+)- \\
\text { mannose, mannose, carubinose, seminose }]\end{array}$ & $3458-28-4$ & $\sim 16306$ & 16310 \\
\hline L-mannose L-2h & $10030-80-5$ & $\sim 216$ & 216 \\
\hline $\begin{array}{l}\text { mannose DL-2h [DL-mannose, }( \pm) \text {-mannose, dl- } \\
\text { mannose }\end{array}$ & $31103-86-3$ & $\sim 82$ & 6865 \\
\hline D-talose D-2i [D-(+)-talose $]$ & $2595-98-4$ & $\sim 286$ & 286 \\
\hline L-talose L-2i & $23567-25-1$ & $\sim 41$ & 41 \\
\hline talose DL-2i [dl-talose] & $30077-17-9$ & $\sim 283$ & 283 \\
\hline
\end{tabular}


Table 3. 2-Ketohexoses 3 in Chemical Abstracts

\begin{tabular}{|c|c|c|c|}
\hline CA name [other names] & $\mathrm{RN}$ & $\begin{array}{l}\text { number of } \\
\text { references } \\
\text { indicated in the } \\
\text { Registry File }\end{array}$ & $\begin{array}{l}\text { number of } \\
\text { references } \\
\text { retrieved in the CA } \\
\text { File }\end{array}$ \\
\hline $\begin{array}{l}\text { D-fructose D-3a [D-(-)-fructose, D-(-)- } \\
\text { levulose, fructose, levulose, fruit sugar, } \\
\text { D-arabino-2-hexulose] }\end{array}$ & $57-48-7$ & $\sim 34145$ & 34200 \\
\hline L-fructose L-3a & $7776-48-9$ & $\sim 167$ & 167 \\
\hline $\begin{array}{l}\text { fructose DL-3a [DL-fructose, }( \pm \text { )-fructose, } \\
\text { dl-fructose, methose, arabino-2- } \\
\text { hexulose] }\end{array}$ & $30237-26-4$ & $\sim 76$ & 10623 \\
\hline $\begin{array}{l}\text { D-psicose D-3b [D-allulose, D-ribo-2- } \\
\text { hexulose }]\end{array}$ & $551-68-8$ & $\sim 218$ & 218 \\
\hline L-psicose L-3b [L-ribo-2-hexulose] & $16354-64-6$ & $\sim 35$ & 35 \\
\hline $\begin{array}{l}\text { psicose DL-3b [DL-psicose, allulose, } \\
\text { erythrohexulose, pseudofructose, ribo-2- } \\
\text { hexulose] }\end{array}$ & $23140-52-5$ & $\sim 148$ & 174 \\
\hline $\begin{array}{l}\text { D-sorbose D-3c [D-(+)-sorbose, sorbinose, } \\
\text { D-xylo-2-hexulose] }\end{array}$ & $3615-56-3$ & $\sim 25280$ & 25292 \\
\hline $\begin{array}{l}\text { L-sorbose L-3c [L-(-)-sorbose, } \\
\text { sorbinose, L-xylo-2-hexulose, L-1,3,4,5,6- } \\
\text { pentahydroxyhex-an-2-one] }\end{array}$ & $87-79-6$ & $\sim 2491$ & 2492 \\
\hline $\begin{array}{l}\text { L-sorbose (incompletely defined } \\
\text { substance) L-3c }\end{array}$ & $97806-30-9$ & 0 & 0 \\
\hline $\begin{array}{l}\text { sorbose DL-3c [DL-sorbose, }( \pm) \text {-sorbose, } \\
\text { dl-sorbose, } x y l o-2 \text {-hexulose] }\end{array}$ & $3615-39-2$ & $\sim 35$ & 441 \\
\hline D-tagatose D-3d [D-lyxo-2-hexulose] & $87-81-0$ & $\sim 365$ & 365 \\
\hline L-tagatose L-3d [L-lyxo-2-hexulose] & $17598-82-2$ & $\sim 43$ & 43 \\
\hline $\begin{array}{l}\text { tagatose DL-3d [DL-tagatose, lyxo-2- } \\
\text { hexulose] }\end{array}$ & $17598-81-1$ & $\sim 325$ & 400 \\
\hline
\end{tabular}

\section{Racemic carbohydrates in CAS}

To sum it up the CA names and registry numbers assigned to the 'racemates' arabinose [147-819], lyxose [65-42-9], ribose [34466-20-1], xylose [25990-60-7] (cf. Table 1), allose [5038-51-3], altrose [5987-68-8], galactose [26566-61-0], glucose [58367-01-4], gulose [19163,87-2], idose [2152-76-3], mannose [31103-86-3], talose [30077-17-9] (cf. Table 2), fructose [30237-26-4], psicose [23140-52-5], sorbose [3615-39-2], and tagatose [17598-81-1] (cf. Table 3) do not and 
cannot refer to any racemates and are thus unsuitable to retrieve any useful information (cf. Tables 1, 2, and 3).

Typical hits for 'glucose' [58367-01-4] retrieve references dealing with subjects such as 'glucose tolerance test' or glucose as pharmaceutical excipient, without any even remote involvement of DL-glucose DL-2d.

The corresponding sugar hemiacetals such as glucopyranose [54-17-1] with 89 associated references and $\beta$-galactofuranose [131064-96-5] with 4 associated references receive a corresponding unsound treatment as undocumented racemates. For the sake of brevity we refrain from elaborating further details here.

\section{Conclusions}

It appears that poor documentalistic practices have been allowed to create a niche of virtual carbohydrate chemistry in the CA Registry File which is apt to confuse novices and to baffle practicing organic chemists or documentalists. As could be expected a priori and as confirmed by numerous spot checks none of the references linked to the racemic carbohydrates and their registry numbers do in fact mention them, explicitly or implicitly.

\section{References}

1. Eliel, E. L.; Wilen, S. H. Stereochemistry of Organic Compounds, John Wiley \& Sons, Inc.: New York etc., 1994.

2. Belitz, H.-D.; Schieberle, P.; Grosch, W. Food Chemistry, 3rd Ed., Springer: Berlin, 2004.

3. http://www.cas.org/products/sfacad/index.html.

4. http://www.cas.org/support/academic. 


\section{Authors' biographical data}

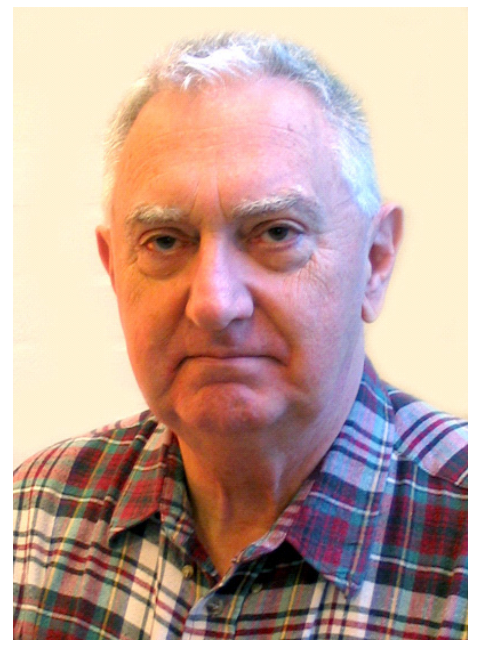

Alexander Senning was born in 1936 in Riga, Latvia. He studied chemistry at Munich, Germany (1954-59) and Uppsala, Sweden (1960-62). He obtained a Ph.D. in organic chemistry from Uppsala University (1962), joined the Department of Chemistry, Aarhus University, Denmark as assistant professor (1962-65) and served as associate professor during 1965-93. During a sabbatical leave (1973-75) he was head of the research laboratory of the drug company A/S Alfred Benzon, Copenhagen, Denmark. He joined the Danish Engineering Academy (DIA), Lyngby, Denmark, later part of the Technical University of Denmark (DTU), Kgs. Lyngby, Denmark, as professor of organic chemistry in 1993, until his retirement in 2003. Alexander Senning is the author of Elsevier's Dictionary of Chemoetymology, published in 2006. His research interests include organic sulfur chemistry and medicinal chemistry. He has been intensively involved as a journal and handbook editor. 